\title{
fabricación de cal en horno rotatorio; mejora de la calidad y aumento de la productividad
}

(Das Brennen von Kalk im Drehofen)

A. A. LILL

De: «Tsement», voI, 22, núm. 3, 1956, pág. 24*

En el año 1953, en la fábrica de cemento Norilsk, que contaba con dos hornos rotatorios de $46 \mathrm{~m}$ de largo, se emprendieron unos ensayos sobre fabricación de cal, por vía húmeda, en horno rotatorio. La pasta cruda tenia un $40 \%$ de agua. Estos ensayos no condujeron a ningún resultado satisfactorio; las pérdidas de polvo eran muy considerables y el consumo específico de combustible demasiado elevado.

Por estas razones, en 1954 se cambió la línea general de los ensayos, dirigiéndolos hacia la fabricación de cal, por el procedimiento de vía seca, también en horno rotatorio.

El horno y el enfriador utilizados presentaban las siguientes caracteristicas, respectivamente: longitud, 46 y $20 \mathrm{~m}$; diámetro, 2,0/2,5 y $1,6 \mathrm{~m}$; pendiente, 3,5 y $5,0 \%$; vueltas por minuto, $1,0 / 1,5$ y 2,5. El revestimiento del horno estaba constituido por ladrillos de cromo-magnesita, en la zona de sinterización, y de chamota, en el resto.

El tamaño óptimo de los trozós de caliza era de $20 \ldots 50 \mathrm{~mm}$, según se determinó en ensayos preliminares; con estos tamaños, el contenido en $(\mathrm{CaO}+\mathrm{MgO})$ era del $85 \%$, e incluso superior. Los trozos y partículas con un tamaño inferior a $20 \mathrm{~mm}$ determinaban una produccín de polvo muy intensa, y no contribuían, en absoluto, a mejorar la calidad. Además, la cal que se obtenía. a partir de dichos granos resultaba muy o poco cocida.

El contenido en $\mathrm{CaCO}_{3}$ era de $94,6 \%$. Como combustible se utilizó carbón pulverizado, con una potencia caloríflca de $5.500 \mathrm{kcal} / \mathrm{kg}$, y una finura tal, que dejaba un rechazo del orden del $8 \%$ en el tamiz núm. 90. El punto de fusión tan bajo de las calizas, condujo a la formación de anillos en el horno. En general, la cocción se realizó en atmósfera oxidante. El rendímiento del horno fué de $4,5 \mathrm{t} / \mathrm{h}$. Fl consumo de combustible ascendió a $350 \ldots 360 \mathrm{~kg} / \mathrm{t}$ de cal. La calldad de la cal obtenida fue muy superior a la procedente de cualquier horno vertical; su contenido en $\mathrm{CaO}$ era del orden de $85 \%$, mientras que en la procedente de hornos verticales no es nunca superior al $70 \%$.

El proceso de cocción, que permitió alcanzar estos resultados, queđa caracterizado por los siguientes datos:

Temperatura en la zona de combustión: $1.250 \ldots 1.300^{\circ} \mathrm{C}$.

- En aSilikattechnikn, vol. 7, núm. 12, diciembre 1956, Dag. 528. 
Temperatura de los gases de escape: $550^{\circ} \mathrm{C}$.

Vacío en la cámara de polvo: $12 \ldots 14 \mathrm{~mm} / \mathrm{Hg}$

Consumo de aire primario: $20 \%$.

Velocidad de la mezcla aire-combustible, a la salida de la boquilla: $46 \mathrm{~m} / \mathrm{s}$.

Comparando los resultados obtenidos en un horno rotatorio y en uno vertical moderno, pueden establecerse las sigulentes conclusiones:

a) El horno rotatöio permite conseguir un control uniforme del proceso, así como fabricar una cal de excelente calidad.

b) Si la cocción se lleva a cabo en horno rotatorio, pueden emplearse trozos de callza con tamaños điversos, oscilando entre 20 y $50 \mathrm{~mm}$.

c) El número de operarios necesarios para realizar la fabricación de cal en horno rotatorio es considerablemente inferior al de los que se necesitan para levar a cabo dicha operación en horno vertical, de modo que se puede aftrmar que se eleva la productividad.

S. F. S. 